\title{
Modelling the Turbocharger Cut Off Application Due to Slow Steaming Operation 12RTA96C-B Engine
}

\author{
Karsten Wehner ${ }^{1}$, Hartmut Schmidt ${ }^{2}$, Muhammad Ramadhan Pamungkas ${ }^{3}$
}

\begin{abstract}
In view of the global economic situation and the rising oil prices, shipowners and charterers are looking for solutions to cut costs by reducing fuel consumption. Low load operation, also well-known as "slow steaming", represents the currently most effective and popular measure to cut fuel costs and, in consequence, the total operational costs for increased competitiveness in the market. Low load operation is possible and there is an increasing trend to operate in these very low engine load ranges. As the engines were not designed for this operational condition, various retrofit modifications to the engine can compensate for this. By using low load operation, the reduction of the RPM gives problems when sailing at low speed. A turbocharger (TC) compresses inlet air to a high pressure and after cooling this compressed air it results in higher mass of air in the cylinder. But when running at a low power load this air reaches temperatures that are too low for an optimal combustion process. One of the solution comes from the company Wärtsilä. They install so called "low steam engine kits". When this kit is installed it allows the engine operators to cut off one turbocharger of the engine, this result's in a higher RPM for the operating turbochargers. When the remaining TC's have a higher RPM their efficiency improves and gives the engine more air for combustion. The purpose of this research is to make a calculation modelling and prove that by switching off one or more turbocharger on the system will improve the efficiency in slow steaming operation. Beside that, this research is aims to estimated the performance of the engine in both operation condition.
\end{abstract}

Keywords - slow steaming, turbocharger cut off, 12RTA96C-B engine.

\section{INTRODUCTION}

Ships commonly sail at the most economic speed.

This is the speed where the engines are originally designed for. The optimal load range engine lies between $70-85 \%$. The fuel efficiency of the engine, its operational parameters, the specification of the turbochargers, coolers, auxiliary systems, exhaust gas boilers, and so on, are chosen and optimised for that normal load range. But when the engine is operated continuously in a load range below or even far below $60 \%$, the overall system is no longer fully optimized [1-5]. Recently, more ships demand to sail at lower speeds because the high speed is no longer needed due to economical section. The problem is that this is not useful to do because of the lower efficiency on these speeds. Therefore, the main question is how is it possible to sail at a low speed without losing any efficiency?

Engine's on big vessels have their own optimal load on which the efficiency of the engine is highest. When we slow down and without any adjustments to the propulsion system, the efficiency will drop down enormously. The following subjects are the most interesting to investigate when we sail at a lower speed: the cooling system, the combustion process, the turbocharger, the lubrication oil system and the engines wear and the fuel consumption. The subjects will be discussed on how the turbocharger can be adjusted to raise the efficiency on a lower speed [6-7].

Karsten Wehner, Maritime Department, Hochschule Wismar, Rostock, Germany, Email: karsten.wehner@hs-wismar.de

Hartmut Schmidt, Maritime Department, Hochschule Wismar, Rostock, Germany, Email: hartmut.schmidt@hs-wismar.de

Muhammad Ramadhan Pamungkas, Department of Marine Engineering, Institut Teknologi Sepuluh Nopember, Kampus ITS Sukolilo-Surabaya 60111,Indonesia, Email: ramadhanpam@gmail.com
The reduction of the RPM gives problems when sailing at low speed. A turbocharger (TC) compresses inlet air to a high pressure and after cooling this compressed air it results in higher mass of air in the cylinder. But when running at a low power load this air reaches temperatures that are too low for an optimal combustion process. The main issue of slow speed steaming is the low RPM of the turbochargers [8-10].

On engines with two or more turbochargers, this can be overcome by applicating a turbocharger cut-off method. Thereby, the performance of the remaining turbochargers will be improved from running at higher revolutions, which again reduces the fuel oil consumption further because the better quality of the air that delivered into the combustion chamber. In this research, then result of modeling are displayed in the form of performance curves. Where in the curve we can see the performance of the engine in the normal operation condition with $3 \mathrm{TC}$ and performance when TC cut off is performed in the low load operation [9-10].

Ships commonly sail in slow steaming condition which means that ship is sailing at the most economic speed. There is a lot of factor why the ships nowadays is operating in slow steaming condition, such as the global economy turndown, environmental regulation on emission, the financial crisis, the sudden fall in ship values, high fuel cost and many more.

The fuel efficiency of the engine, its operational parameters, the specification of the turbochargers, coolers, auxiliary systems, exhaust gas boilers, and so on, are chosen and optimized for that normal load range. It is natural, therefore, that when the engine is operated continuously in a load range below or even far below $60 \%$, the overall system is no longer fully optimized.

Wärtsilä has investigated the various concerns that have been raised across the low load range, different engine conditions can be observed. 
One of the problem is insufficient air supply to system when slow steaming is performed. The reduction of the RPM gives problems when sailing at low speed. A turbocharger (TC) compresses inlet air to a high pressure and after cooling this compressed air it results in higher mass of air in the cylinder. But when running at a low power load this air reaches temperatures that are too low for an optimal combustion process [9-13].

One of the solution comes from company Wartsilla. they install so called low steam engine kits. When this kit is installed it allows the engine operators to cut off one turbocharger of the engine, this result's in a higher RPM for the operating turbochargers. The higher load of the other turbochargers will result in higher inlet air temperatures but this is no problem for the overall process. When the remaining TC's have a higher RPM their efficiency improves and gives the engine more air for combustion.

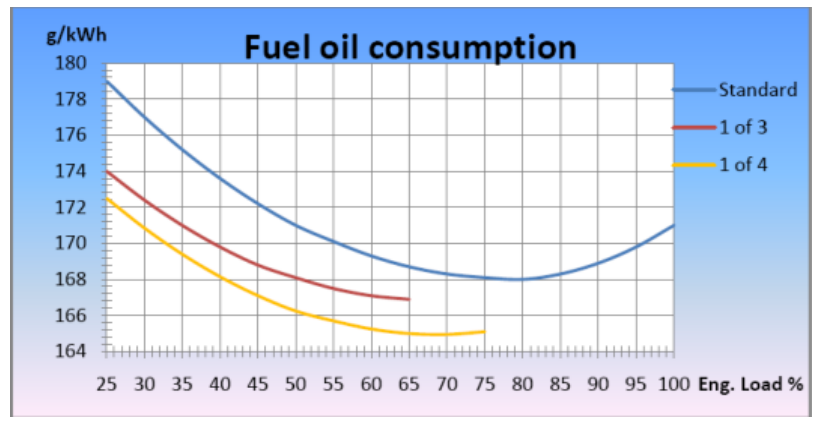

Figure. 1. SFOC vs Engine Load

Engines with four turbochargers and one turbocharger cut-out enables operation at loads from $20 \%$ to $70 \%$ MCR:

- Approx. $5 \mathrm{~g} / \mathrm{kwh}$ reduction of SFOC and $0.33 \mathrm{bar}$ increase in scavenge air pressure at $50 \%$ power. (1 $\mathrm{T} / \mathrm{C}$ cut-out of $4 \mathrm{~T} / \mathrm{Cs}$ )

- Approx. 3g/kwh reduction of SFOC and $0.40 \mathrm{bar}$ increase in scavenge air pressure at $75 \%$ power. (1 $\mathrm{T} / \mathrm{C}$ cut-out of $4 \mathrm{~T} / \mathrm{Cs}$ )

The solution to cut off one turbocharger is also done by MAN B\&W. MAN B\&W achieves to cut out a turbocharger with blind plates or valves. The following information is received from MAN during field research. The best way to cut off a turbocharger is done by valves. These valves can be operated simply by hand after the operators have slowed down the engine to low load operation.

\section{METHOD}

Methodology of this paper is described in 2 . Workflow of this paper is started from collecting data, The data used in this research is the data of 12RTA96C$\mathrm{B}$ engine operation. Data for this analysis will be collected from engine specification and turbocharger specification.

Then analysis the characteristic of turbocharger based on engine performance parameter and the turbocharger cut off modification is done by making a mathematical model. The data collected will be used for making this calculation simulation. The simulation compared between the initial of turbocharger with the data of turbocharger that already modified by turbocharger cut off method with the same engine specification.

After analysis the model is validate. At this stage, the output data from simulation process not exactly resulted the correct data of the performance. The output data obtained as a result from engine simulation might be had some of error. The modelling result is compared with reference data from TEKOMAR line.

Conclusions are expected in this research is able to answer the problem. This research aims to calculate and estimate the engine performance. Written advice based on data from the discussion well as the fact that there is, and given to the improvement of this Paper in order to become better. 


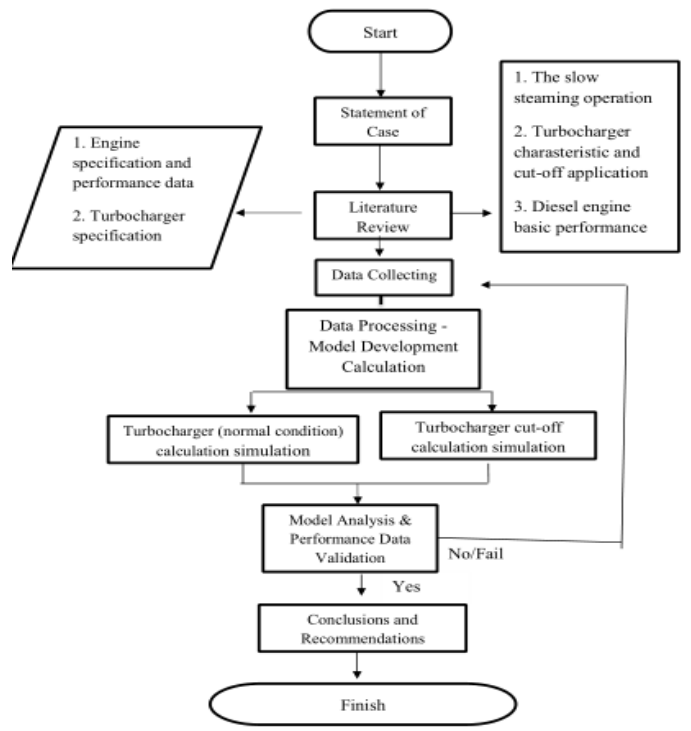

Figure. 2. Methodology

A. Basis

Due to the constantly increasing demands on the company in recent years of using slow steaming operation, most of them is performing a more thoroughly monitoring and evaluation of their engine performance. Ships owners start paying more attention to their engine fuel consumption, the efficiency and also the pollutant emissions. There still quite industry that has experiencecy growth in this case in recent years. In normal operation, the evaluation is performed by testing the engine engine directly and evaluating the test bench. These record of the actual state is compared with the record from the engine maker, since the record is evaluate the same operation this will be easy to evalute.

The analysis of the differences between the record from the test and from the engine maker, it allows to predict the unintentional of events that may affect potential improvement or malfunctions in the machine operation. By using turbo-off technology, it will make some operating parameters value of the engine change significantly. Because this is a case of a result of operation at low load, so there is no comparative data. To monitor and evaluate this motor, it is necessary to a quality prediction or modelling of the changed operating parameters. The following model was created from this purpose.

The goal is to develop a workable model on a wide variety of Turbocharger engine configurations. So the future of this model is expected to be the basis for calculation when evaluating engine performance. So, from the beginning, a lot of simplification and idealization should be done so that calculations can be done more precisely.

B. Engine Report Data

The basic calculation is an 12RTA96C-B engine performance report. 12RTA96C-B engine is built by Wartsilla company. The data for this research is obtained from MARIDIS Company. There There are 2 data, the data from the engine test and also reference data from TEKOMAR prediction result as a result comparasion with this model. It contains the following data.

TABLE. 1 . ENGINE PERFORMANCE DATA TEST OF 12RTA96C-B

\begin{tabular}{|c|c|c|c|c|c|c|c|}
\hline & Unit & 0.25 & 0.5 & 0.75 & 0.9 & 1 & 1.1 \\
\hline BHP & $H P$ & 23340 & 46680 & 70020 & 84024 & 933660 & 102696 \\
\hline Rated Power & $k W$ & 17404.6 & 34809.3 & 52213.9 & 62656.7 & 696230.3 & 76580.4 \\
\hline Engine Speed (rpm) & $1 / \min$ & 64.26 & 90.96 & 92.67 & 102 & 102 & 105.29 \\
\hline Fuel Oil Constumption & $\mathrm{kg} / \mathrm{h}$ & 3205.17 & 6127.48 & 8976.89 & 10908.28 & 12274 & 13944 \\
\hline SFOC & $g / k w h$ & 184.16 & 176.03 & 171.93 & 174.10 & 17.63 & 182.08 \\
\hline Cylinder Pressure (max) & bar & 65.6 & 99.4 & 131.2 & 140.1 & 141.9 & 145.1 \\
\hline Cylinder Pressure (comp) & bar & 44.8 & 72 & 107.2 & 125.3 & 139.3 & 151 \\
\hline P Scavenge & bar & 1.24 & 2.02 & 3.02 & 3.53 & 3.85 & 4.16 \\
\hline P Exhaust & bar & 1.19 & 1.76 & 2.55 & 2.97 & 3.28 & 3.36 \\
\hline $\mathrm{P}$ environment & bar & 1.032 & 1.032 & 1.032 & 1.032 & 1.032 & 1.032 \\
\hline $\mathrm{T}$ after Cylinder (T4) & $K$ & 608.3 & 608.4 & 611.5 & 637.6 & 671.3 & 713.8 \\
\hline $\mathrm{T}$ before Turbine (T5) & $K$ & 653 & 678 & 683 & 715 & 753 & 808 \\
\hline $\mathrm{T}$ after Turbine (T6) & $K$ & 613 & 602 & 555 & 556 & 580 & 618 \\
\hline T surroundings & $K$ & 298 & 298 & 298 & 298 & 298 & 298 \\
\hline Turbocharger Speed (rpm) & $1 / \min$ & 3625 & 6730 & 8710 & 9480 & 10070 & 10620 \\
\hline
\end{tabular}


C. Reference Modelling.

The first step was to create a simplified engine model scheme. It forms of the cylinder, the turbocharger consisting of turbine and compressor, and the charge air cooler. The charge air cooler was efficiency is regarded as ideal for this view. The inlet air cooler temperature is constant on $17{ }^{\circ} \mathrm{C}$. For the environmental condition are state to be a constant value, where the temperature is 20 ${ }^{\circ} \mathrm{C} / 293 \mathrm{~K}$ and the pressure value is $1.032 \mathrm{bar}$. The next figure shows the engine cycle scheme used, dnd the pressure and temperature are included. Table 2 shows the the picture of it.

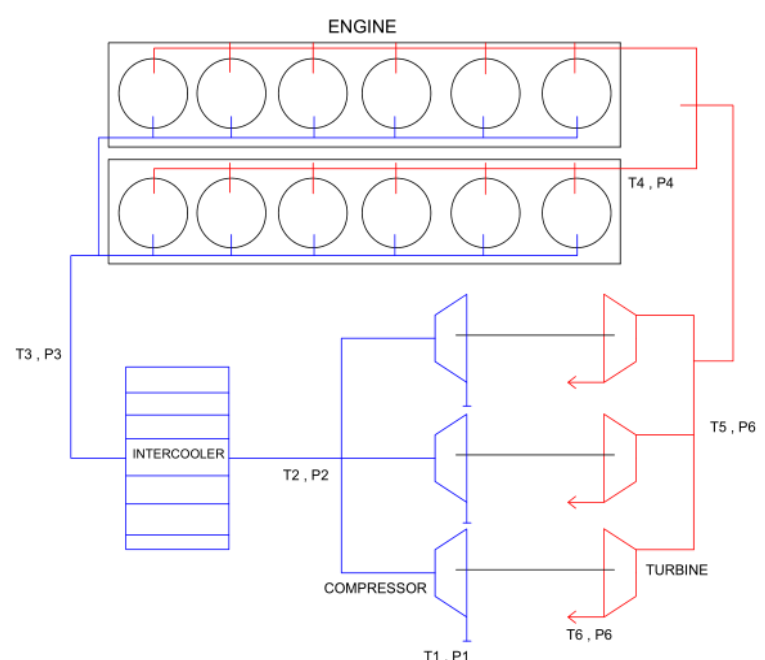

Figure. 3. Model Cycle Scheme

TABLE 2.

SCHEME VARIABLE EXPLANATION

\begin{tabular}{cl}
\hline Parameter & \multicolumn{1}{c}{ Explanation } \\
\hline T1, P1 & $\begin{array}{l}\text { Surrounding temperature and pressure } \\
\text { (Intake) constant at 293K and 1032 mbar }\end{array}$ \\
T2, P2 & $\begin{array}{l}\text { Temperature and pressure after compressor } \\
\text { (Scavange air) }\end{array}$ \\
T3, P3 & $\begin{array}{l}\text { Temperature and pressure after scavange air } \\
\text { cooler (before cylinder) }\end{array}$ \\
T4, P4 & Temperature and pressure after cylinder \\
T5, P5 & Temperature and pressure before turbine \\
T6, P6 & Temperature and pressure after turbine \\
\hline
\end{tabular}

The first cycle of the calculation is aimed to determine some required value of the thermodynamic model that will be used in the further calculation..

1. Exhaust gas energy

Exhaust gas energy is the residual energy from the combustion process that goes out through the exhaust valve. Exhaust gas energy is one form the of energy distributed in the cylinder.

$\mathbf{Q}_{\text {in }} / \mathbf{Q}_{\text {fuel }}=\mathbf{Q}_{\text {exhaust }}+\mathbf{P}_{\mathbf{i}}+\mathbf{Q}_{\text {wall heat losses }}$

The fuel energy is the amount of heat that is released during the combustion of specified amount of it. For this research model can be assumed that fuel energy is a result of the sum of exhaust energy, indicated power, and wall heat losses energy. The input power can be calculated by cultiplying the specific fuel consumption at certain load points, the effective power and the lower calorific value.

$\mathbf{Q}_{\text {fuel }}=(\mathbf{S F O C})$ be $* \mathbf{P}_{\mathrm{e}} * \mathbf{H}_{\mathbf{u}}$

Indicated power is the theoretical maximum output power of the engine. The indicated power is the total power produced from the expanding of the gases in the cylinders negating any heat loss or entropy within the system.

$\mathbf{P}_{\mathrm{i}}=\mathbf{Q}_{\text {in/fuel }} * \boldsymbol{\eta}_{\mathrm{i}} / \mathbf{P}_{\mathrm{i}}=\mathbf{P}_{\mathrm{e}} / \boldsymbol{\eta}_{\mathrm{m}}$

By comparing the actual fuel burning power with the indicate power that goes into the piston we can acquire indicate efficiency. The theoritical assumption of indicate effieciency value is $55 \%$ of the total power, and it is assumed the value constant in the overall load range for this research modelling.

The wall heat losses is the losses of the heat energy that transfered from the combustion chamber to the engine block and system. Theoretically the losses were accepted for the full-load by 21-23\% losses of the input energy. By lowering the engine power, then the value of losses will be also gradually reduced. The map of the losses and the load range is shown in the graph next.

The curves are represent the percentage of heat loss distribution based on the fuel power consumption as function of the engine load. The curves are valid after up to 4 months operation using heavy fuel oil. From the wall heat losses graph figured, theses heat losses coefficient function were obtained. 


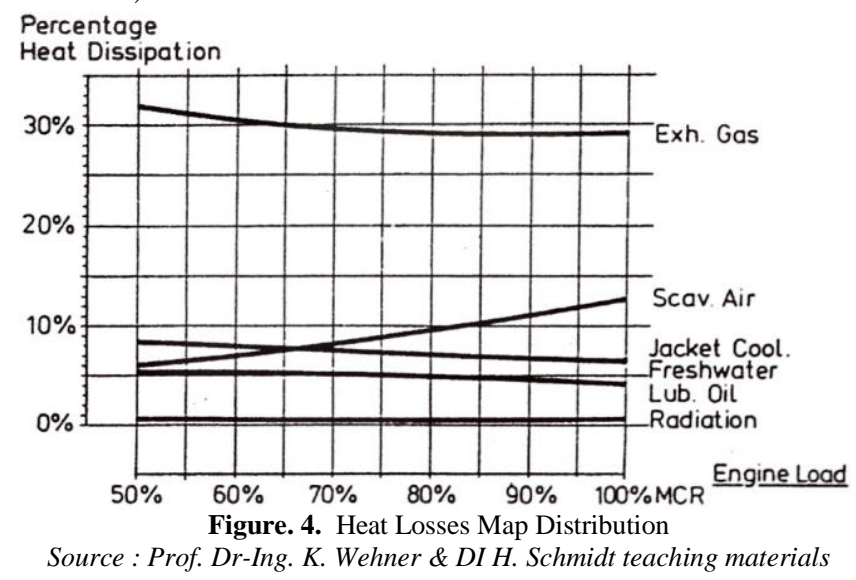

\section{Exhaust gas mass flow}

In the next step mass flow of the exhaust gas can be determined, by using the temperature inlet (T3) and outlet (T4) value of the cylinder from the engine data test. The formula of the exhaust gas value mentioned below.

$\mathbf{m}_{\text {exhaust }}=\mathbf{Q}_{\text {exhaust }} / C p_{\text {exhaust }} *\left(\mathbf{T}_{4}-\mathbf{T}_{3}\right)$

In the next step of calculation is to calculated the fresh air mass flow rate. The value can be obtained by subtracting the fuel mass flow from exhaust gas mass flow.

3. Fresh air mass flow.

$\mathbf{m}_{\text {fresh air }}=\mathbf{m}_{\text {exhaust }}-\mathbf{m}_{\text {fuel }}$
After getting the value of mass flow, now it is possible to make the operating line compressor. Since the fresh air mass flow is generated in normal operation by three compressors, the first step is to divide the fresh air mass flow value for 3 compressors.

4. Mass flow standard coefficient

$m_{\text {standard coefficient }}=m_{\text {freshair }} \times(T 1)^{0.5} / \mathbf{P 1}$

Performance of a compressor is usually specified by curves of delivery pressure against mass flow rate for various fixed values of rotational speed and inlet temperature. These performance characteristic curves are usually plotted with dimensionless variables.

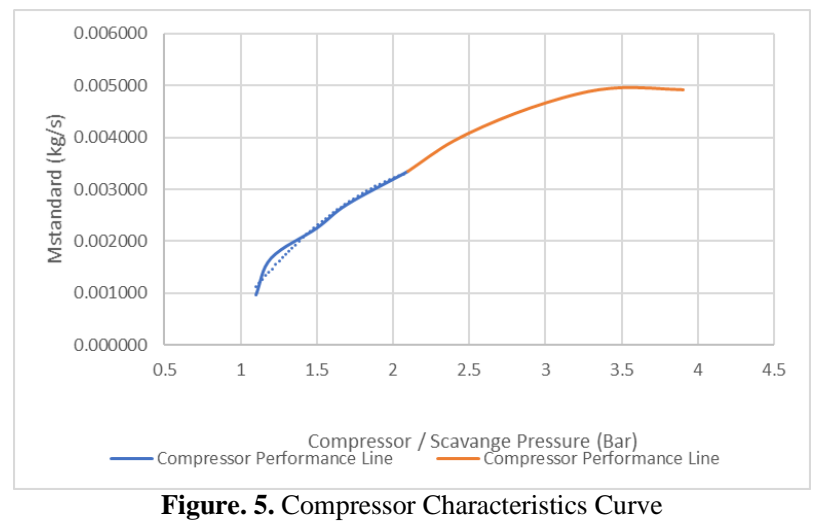

From the curve, 2 mass flow standard function based on scavenge air pressure (p2) were set.

- Mstandard $(\mathrm{p} 2)=(0.005649859+(-1555.386-$ $0.005649859) /\left(1+(\mathrm{P} / 0.000004907295)^{\wedge} 1.033987\right)-$ $0.0001)$

- $\quad$ Mstandard $(\mathrm{p} 2)=(0.004956387+(0.003809266-$ $0.004956387) /\left(1+(\mathrm{P} / 2.747092)^{\wedge} 15.28802\right)-0.0003$

5. Kinetic energy transfer in exhaust manifold

In the turbocompressor supply system, successive pulses of hot exhaust gas which leave the engine cylinders compress adiabatically the gas column situated in front of them. The increasing hydraulic resistance slows down the flow and provokes dissipation of kinetic energy of the compressed fluid. The observable symptoms of which are the decrease of the exhaust gas flow velocity and the increase of its static temperature and pressure in the turbocompressor turbine crosssection.

$E_{k}$ transferred $=m \times C^{2} / 2=m$ Cp $($ T5-T4)

6. Turbine and compressor efficiency

In the analysis, isentropic efficiency is a parameter to measure the degree of degradation of energy in steady-flow devices. It involves a comparison between the actual performance of a device and the performance that would be achieved under idealized circumstances for the same inlet and exit states.

For the turbine and compressor efficiency value for this research is adapted to the turbocharger curves from MAN B\&W company. This curves are valid for all type of diesel engine with bore more than $50 \mathrm{~cm}$. Its show the relation of pressure over the effciency. 


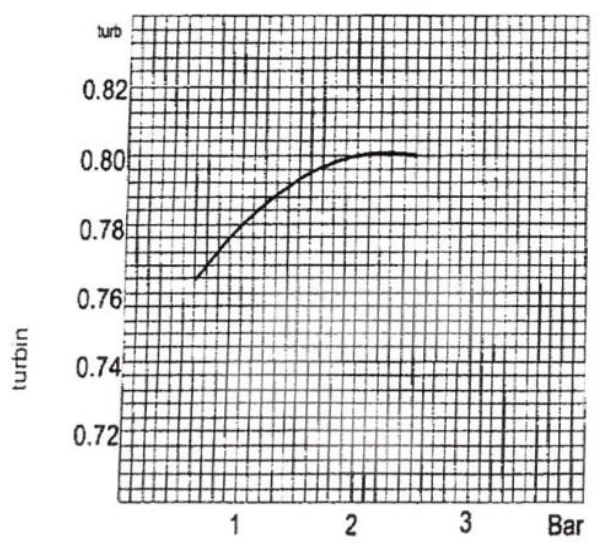

Figure. 6. Compressor and Turbine characteristic curves

7. Turbine and Compressor Power

The heat transfer in and out of a turbine can typically be considered negligible as well as the potential energy unless otherwise stated. In this step, the power of each turbine is determined by this formula.

$P_{T}=\frac{\dot{m}_{\text {exhaust }}}{i} * c_{p \text { exhaust }} *\left(T_{5}-T_{6}\right)$

The i represent numbers of turbine. Depended on how many turbines are operated, exhaust gas mass flow is evenly distributed.

Turbine power will be supplied to the compressor by the shaft, and certainly there will be less mechanical losses occurring in this process. Hence for this research assumed that the mechanical efficiency of the turbocharger is $98 \%$.

$P_{\text {compressor }}=P_{T} * \eta_{m, \text { Turbocharger }}$

\section{Compressor temperature (T2) and pressure (P2)}

The next step is to calculate the air condition on compressor outlet. Increasing air compression, that is the amount of gas included in the same volume, at the same time, its temperature is increased. Higher temperature is connected with lower density, which means that cylinders receive the amount of oxygen smaller than if the air temperature were lower. There are 2 indications that show the process that is temperature and pressure after the compressor.

$$
T_{2}=\frac{P_{\text {comp }}}{\left(\dot{m}_{\text {freshair }} * c_{p}\right)}+T_{1}
$$

The next step is to determine the pressure after compressor by using law of polytropic state. The formula mentioned below.

$p_{2}=\left(\frac{T_{2, i s}}{T_{1}}\right)^{\frac{\kappa}{\kappa-1}} p_{1}$

Since the required data has been obtained except the after compressor isentropic temperature (T2,is). Then the step is to calculate the isentropic temperature first using isentrophic efficienct formula and then calculate the pressure after compressor.

$\eta_{i s, C}=\frac{T_{2 i s}-T_{1}}{T_{2}-T_{1}}$

9. Determine new mass flow value of the compressor

In every cycle of calculation, will eventually generate new mass flow value until the result of the calculation shows the results are constant and close to the reference value, in this research the benchmark reference is the performance curve from TEKOMAR company.

Mstandard $(1.42$ bar $)=\frac{(0.005649859+(-1555.386-0.005649859)}{\left.\left(1+(1.42 / 0.000004907295)^{\wedge} 1.033987\right)-0.0001\right)}$

10. Intercooler phase calculation

An intercooler's primary function is to cool the charge air after it has been heated due to boosting and the heat that is produced by the turbo before sending the air into the engine. As the air is cooled, it becomes denser, and denser air makes for better combustion (more power). There will be 2 values that change in this phase, specificaly the value of temperature and pressure. The first step is to calculate the intercooler efficiency.

$\eta_{\text {Cooler }}=\frac{T_{2}-T_{3}}{T_{2}-T_{\text {waterin }}}$

For this research model, the cooling water inlet temperature value used is $290 \mathrm{~K}$. For the gas after cooler temperature value was taken from the engine operation report. This cooler efficiency is assumed to be constant for each engine load operation and it will be used to calculate the gas after cooler temperature in the next cycle of the calculation model. In addition to temperature changes, the pressure value also decreased. The relations between the pressure and the pressure drop is shown in graph below. 


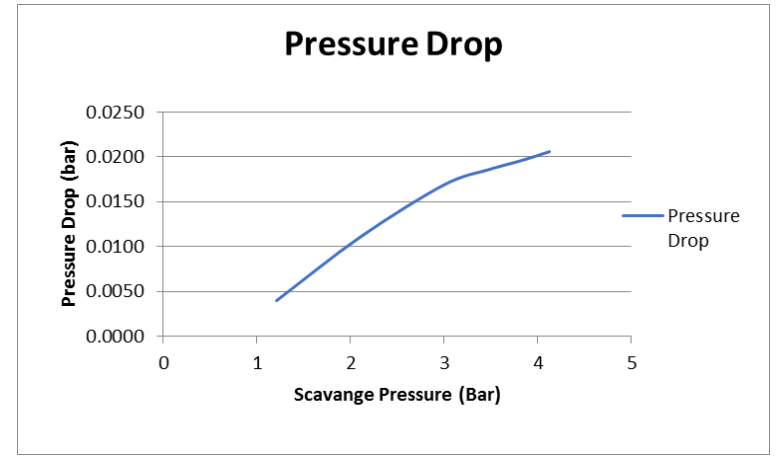

Figure. 7. Pressure Drop Curves

11. Recalculate the scavange compressor (P2) with the first turbocharger equation

This recalculation is performed to get a more precise value of pressure after compressor (P2) with the first turbocharger equation.

$\pi=\frac{P 2}{P 1}=1+\frac{m_{\text {turbine }} \times C p_{\text {turbine }} \times T_{\text {turbine inlet }}}{m_{\text {compressor }} \times C p_{\text {compressor }} \times T_{\text {compressor inlet }}} \times \eta_{T C} \times\left(1-\left(\frac{P 6}{P 5}\right)^{\frac{K T-1}{K T}}\right)^{\frac{K C}{K C-1}}$

For the specific heat ratio or kappa of the exhaust gas $(\mathrm{kT}$ or $\gamma)$, the value is based on the temperature function.

$\mathrm{Y}=\mathrm{\gamma}_{0}-\frac{K_{1}\left(T-T_{\text {reference }}\right)}{1000}$

This is the kappa value function of Gatowski. Where $\gamma 0$ is a reference value (1.38), $\mathrm{K} 1$ is a constant (0.08) and T ref is a reference temperature $(300 \mathrm{~K})$.

For the estimation of surface specific heat ratio of air $(\mathrm{kC})$ as a function of temperature and pressure. For this research estimation of specific heat ratio or kappa for the air value is about 1.36-1.4 it depends on the compressor pressure, The higher the pressure the lower the kappa value. The value for $\mathrm{kC}$ in this research in adaptable due to get the result value as close as possible to the reference value.

Within the overall efficiency of the turbocharger $\eta \mathrm{TC}$ is calculate as

$\eta_{T C}=\eta_{T} \times \eta_{C} \times \eta_{m}$

12. Compression pressure and maximum pressure

The static compression ratio of an internal combustion engine is a value that represents the ratio of the volume of its combustion chamber from its largest capacity to its smallest capacity. In calculating the pressure ratio, assumed that an adiabatic compression is carried out. it can defined the relationship between change of volume and change of pressure as follows: $\frac{\text { Compression Pressure }}{\text { Inlet air pressure }}=\left(\frac{V 1}{V 2}\right)^{\gamma}$

The V1 represent the volume of the cylinder and combustion chamber when the piston is at the bottom of its stroke, meanwhile V2 is the volume of the combustion chamber when the piston is at the top of its stroke. Since the value of V2 is unknown, the initial step is to calculate V2 value that will be used in the next step of this research calculation model.

After the function of the compression pressure determine, the pressure increase value to the maximum compression pressure can be estimated by using function from the curve below. Using the data of maximum pressure from engine report and calculated mass flow, this curve can be made.

- $\quad \Delta \mathrm{P}($ mass flow $)=28.62798+(13.23859-28.62798) /(1$

$+(\mathrm{m} / 44.10621)^{\wedge} 5.357742$ for mass flow $<65 \mathrm{~kg} / \mathrm{s}$

- $\Delta \mathrm{P}$ (mass flow) $=-17187410+(26.03302-$ $17187410) /\left(1+(\mathrm{m} / 183.9695)^{\wedge} 27.47693\right)$ for mass flow $>65 \mathrm{~kg} / \mathrm{s}$

In this first cycle of calculation, the required value and function have been calculated and obtained such as turbine and compressor efficiency, intercooler efficiency, compressor performance function, the kinetic energy value and some other functions and values. These function and value will be used in the next cycle of the performance calculation.

The next step of the calculation to calculate the engine performance in normal condition. This step is aimed to show that thermodynamic model is reliable and can be used in the further calculation.

This whole calculation step is performed at all engine load points. After the calculation in the normal operation is done, the comparasion curves of temperature and pressure is created to show whether the research model calculation is reliable and can be used for further purpose.

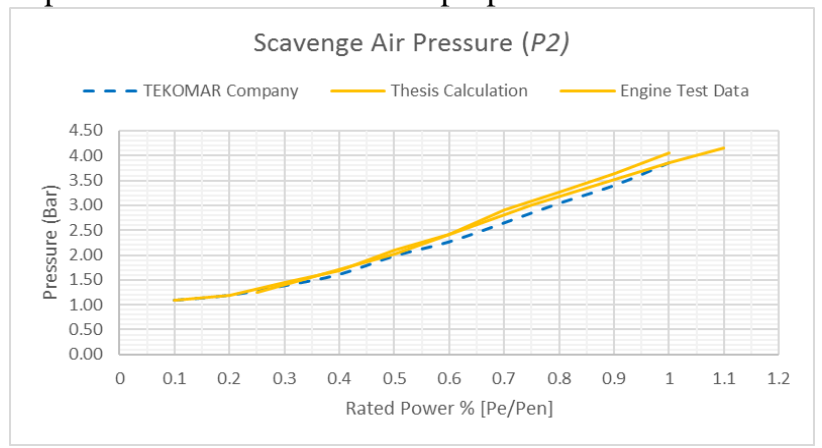

Figure. 8. Scavenge air pressure comparison curves 


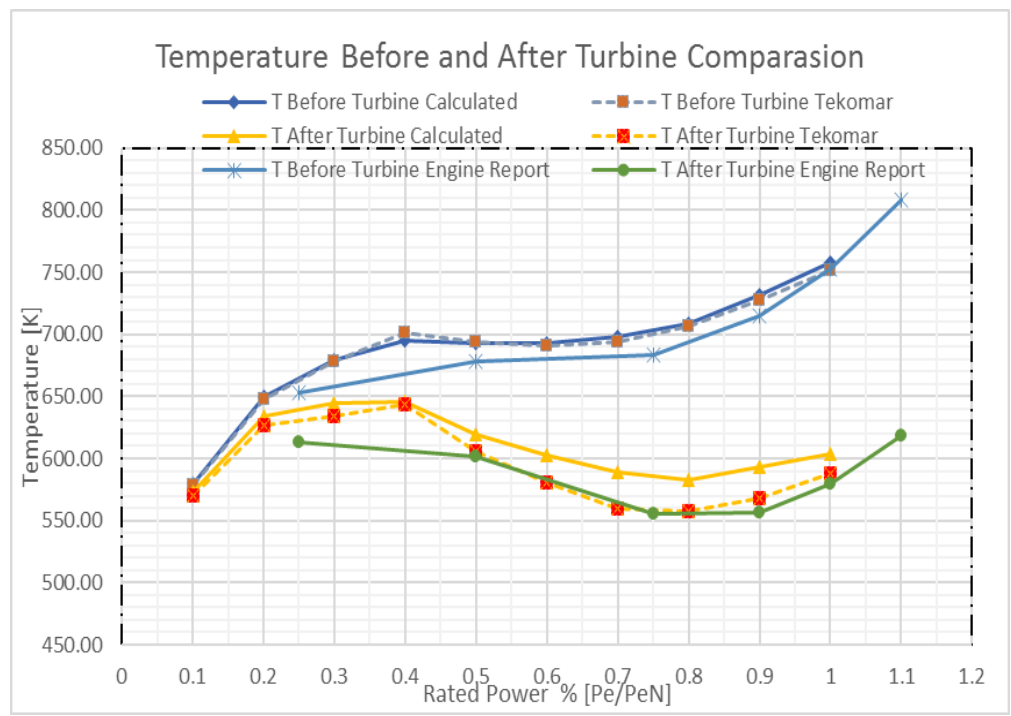

Figure. 9. Temperature before turbine (T5) and after turbine (T6) comparasion curves

As can be seen from the comparison curves of pressure and temperature, there are indeed some differences value between engine report, tekomar, and research model but it is assumed that the deviation value is understandable. This difference in value is likely to be due to differences in specifications and some coefficient values in the calculations such as turbine and compressor efficiency, specific heat ratio, exhaust gas energy value and so on.

The next step of the calculation to calculate the engine performance in 1 turbocharger cut condition. As pratically the slow steaming operation is operated engine in low load operation, this step is aimed to calculate the turbocharger cut off performance in only 10\%-50\% engine load and compare it with the normal condition operation. The calculation step practically the same as the previous calculation but with 2 turbocharger operated. The input value is obtained from the previous calculation.

\section{RESULT AND DISCUSSION}

In this chapter, the performance result obtained is evaluated whether by performing turbocharger cut off will increase the turbocharger efficiency or not. Also the other indicator value will be evaluated and viewed the differences between normal operation performance and the turbocharger cut off performance. The result will also be compared with the TEKOMAR company performance line. The TEKOMAR reference curves are listed on Attachment. These are the comparisons of several aspects.

1. Turbocharger efficiency comparison

As the theory and the application prove that by performing turbocharger cut off in low load range of engine, the turbochager efficiency will improve. The curves below will show it.

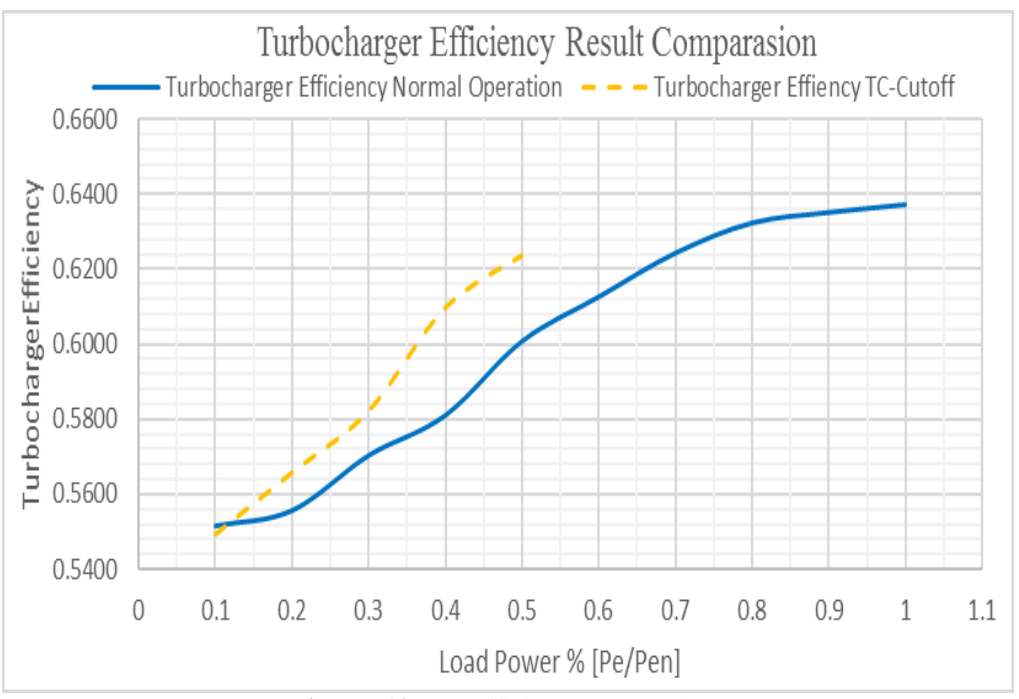

Figure. 10. TC Efficiency Comparison

The result curves show that the turbocharger efficiency is increasing when the TC cut off is performed. By cutting one of the turbine, the exhaust energy will goes only into 2 remaining turbocharger which will eventually increased turbine power and also compressor capacity. Therefore it will increase the fresh air mass flow and also pressure for each compressor. 
2. Mass flow comparison

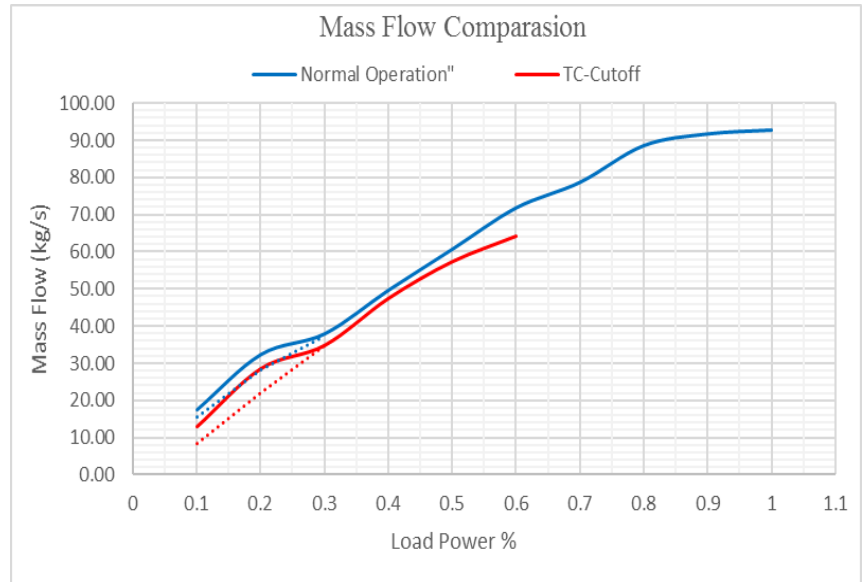

Figure. 11. Mass Flow Comparison

As mentioned before that the compressor power will increase in TC cut off operation, the graph above show the total amount of mass flow that the compressor can drag in to the system. Where for the normal operation there are 3 TC operated and TC cut off is only 2 TC operated.

The influence of the auxiliary blower can be evaluated. The dash line show the normal continued value of the mass flow. As can be seen in the $20 \%$ load shown that the mass flow value is increasing due to the addition of air from the blower. The blower is expected stop operating between $20 \%-30 \%$ engine load, for normal operation blower can bring additional air up to $4.07 \mathrm{~kg} / \mathrm{s}$ meanwhile when TCcut off is performed it can bring more additional air up to $6.69 \mathrm{~kg} / \mathrm{s}$.

\section{Scavenge Pressure Comparison}

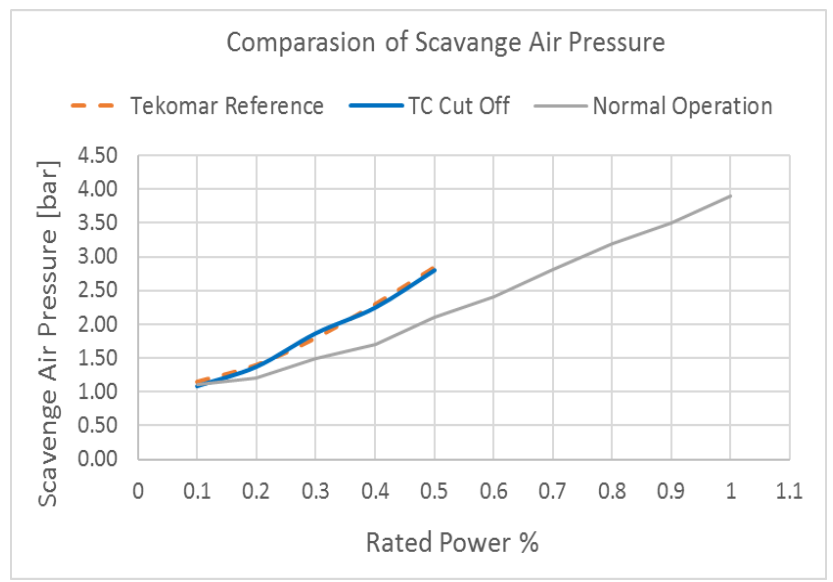

Figure. 12. Scavenge Air Pressure Comparsion

From curves above it is shown that the calculation result is slightly different in $40 \%$ load power from the reference curves due to some differences in calculation background value and coefficient but has the same conclusion, when TC cut off is performed the compressed air pressure is increases.

4. Compression Pressure (Pcomp) and Maximum Compression Comparasion (Pmax)

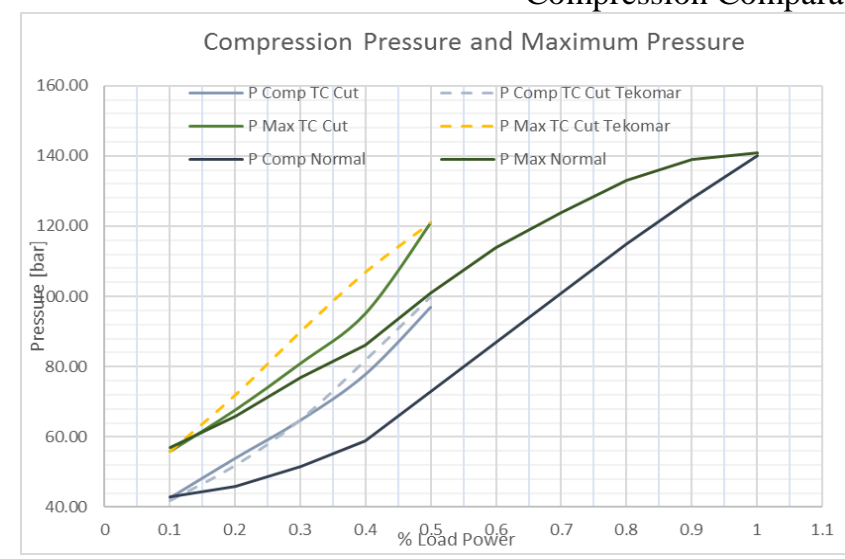

Figure. 13. Compression and Maximum Pressure Comparison Curves 
By using formula 24,25 and 26 , the compression pressure and maximum pressure can be calculated. The result curves shown that theres a little different in value between the research calculation and TEKOMAR curves especially in $20 \%$ and $30 \%$ load power, but both curves shown that the compression pressure and maximum pressure value is increasing when TC cut off is operated. The biggest different between research and TEKOMAR curves is on $40 \%$ load points where the maximum pressure value different is 12 bar.

Due to when we operated the turbocharger cut off the scavange air pressure will increase, it is shown in figure
4.4.3. Therefore the inlet air pressure of the cylinder is higher than the air pressure in normal operation then is causes the compression and maximum pressure of the cylinder will eventually increase.

5. After and Before Turbine Temperature Comparasion The next indication to be compared is the temperature before turbine and after turbine. However the biggest differences value of the research calculation and TEKOMAR line will be found in this section.

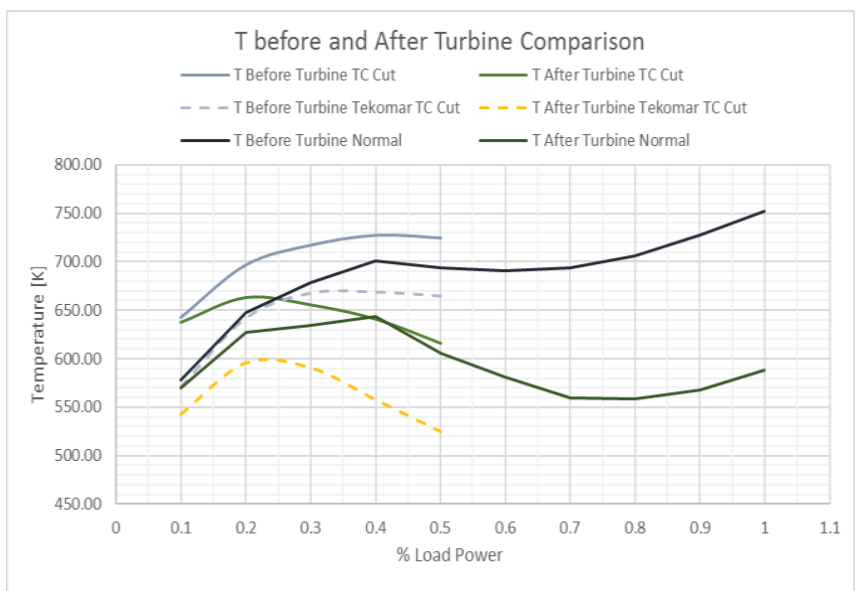

Figure. 14. After and Before Turbine Temperature Comparasion

Figure 14 clearly shows that the research calculation result has a different conclusion with TEKOMAR curves, the research calculation result shown that the temperature before and after turbine in TC cut off operation is higher than the normal operation meanwhile the TEKOMAR curves shows the opposite. As an explanation it can be seen in figure 4.4.2 that TC cut operation drag less amount of air to the engine than the normal operation, but the exhaust gas energy generated between TC cut and normal operation is not much different. It can be concluded that with the quite same energy but the air mass flow is reduced, the temperature will increase and the relation can be seen in formula 27. Furthermore, it can be seen from the calculation curves the effect of the blower support, from $10 \%$ until around 20\%-30\% power the temperature is slightly low due to the blower is supplying additional air the engine.

6. Turbocharger Speed Comparison
By using given data of turbocharger speed and scavenge pressure from the engine report data, a turbocharger characteristics speed function is created.

TCSpeed $f($ scav.pressure $)=\frac{16694.73+(-1444248000-16694.73)}{\left(1+(\text { Scav.Pressure/1.120626e }-8)^{\wedge} 0.6243389\right)}$

By using this function on the calculation result, the comparison curves can be created.

As mentioned before that by performing turbocharger cut off will increase the energy in the remaining turbocharger operated. Therefore it will increase the speed rotation of the turbine and also the compressor which will lead to increased of the fresh air mass flow and also pressure for each compressor. It can be seen that the research calculation curve result has a little difference with the TEKOMAR line due to the compressor pressure result difference. The biggest different can be seen at $20 \%$ load points where the turbocharger speed value diference is almost $500 \mathrm{rpm}$.

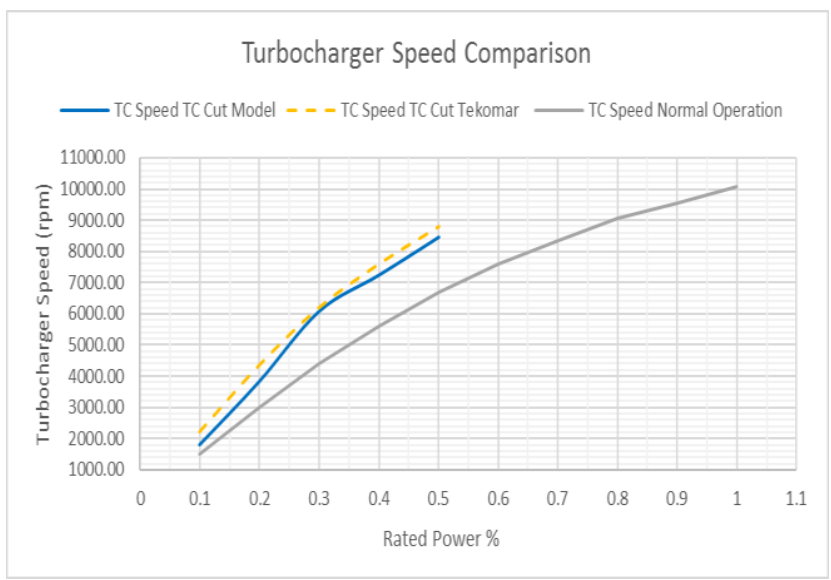

Figure. 15. Turbocharger Speed Comparison 


\section{CONCLUSION}

The slow steaming trend is already part of one of the operating systems on the ship. By using this method there are some technical challenge challenges arise and one of them is the problem of air supply. The turbocharger cut off technology has been widely used among large engines user.

Turbocharger cut off method provide higher RPM and also efficiency on remaining operated turbocharger, which will lead to reducing the fuel oil consumption further because the better quality of the air that delivered into the combustion chamber. In the research mathematical model can be seen that turbocharger cut off method increasing the power of the remaining turbine and compressor, therefore the compressed air will have a higher pressure.

From the result curves (see figure $10-15$ ) in can be conclude that by performing TC cut will significantly changing the engine performance. The scavenge air pressure, temperature before and after turbine, turbocharger speed, turbocharger efficiency, compression pressure all can be conclude that have a significant increase when TC cut is performed.

A comparison with a another model from TEKOMAR curves can be inferred to have a slight difference. But there are still some considerable value difference, especially in temperature modelling section. Therefore, the model created is still potential to be developed. With the expectation of this model can be varied in various machine operations in the future.

\section{REFERENCES}

[1]. Andreas Wiesmann, General Manager Innovation \& Busines Development, Two-stroke, Wärtsilä Services. 2010. Slow steaming- a viable long-term option? Helsinki, Finlandia: Wartsilla Company.

[2]. Bahadori, Alireza. 2011. "Energy Conversion and Management." Estimation of air specific heat ratio at elevated pressures using simple.

[3]. Christiaan Muilwijk, Wouter den Boer, Laurens van der Kooij, Koen Stroomberg. March 31th 2011. Good speed is low speed Efficient low speed sailing. Rotterdam, Netherland: Shipping and Transport College.

[4]. Company, Dosoan Engine Product. n.d. Turbocharger Cut Out System. Seongsan-gu, Changwon-si, Gyeongsangnam-do, South Korea: Doosan.

[5]. Company, GT Suite Product. 2015. GT Suite Software Overview. Westmont, USA: Gamma Technologies.

[6]. Company, Tecumseh Product. 2015. "Detail compressor modeling and bottle cooler simulation." Frankfurt.

[7]. Coorporation, MAN B\&W. 2010. "MAN B\&W K90MC-C6-TII Project Guide." Copenhagen.

[8]. Jääskeläinen, Hannu. 2011. Diesel Exhaust Gas https://www.dieselnet.com/tech/diesel_exh.php.

[9]. Kleimola, Matti. n.d. "Turbocharger Efficiency." Definition and Guidelines for Measurment and Calculation.

[10]. Korczewski, Prof. Zbigniew. 2015. "Exhaust Gas Temperature Measurements In Diagnostics Of Turbocharged Marine Internal Combustion Engines."

[11]. Michael J.Moran, Howard N. Shapiro, Daisie_D.Bo. 1996. Gas Turbine Theory 4th Edition. London: Longman Group.

[12]. Semin, Iswantoro A., Faris F. "Performance and NOx Investigation on Diesel Engine using Cold EGR Spiral Tube: A Review." International Journal of Marine Engineering Innovation and Research., vol. 1, no. 3, Jun. 2017

[13]. Zuhdi A., Busse W., Clausthaldi. "Fluid Flow Analysis of Jacket Cooling System for Marine Diesel Engine 93 KW". International Journal of Marine Engineering Innovation and Research., vol. 1, no. 2, Mar. 2017 